\title{
COMPLEXO DE RAPUNZEL: RELAÇÕES SOCIAIS, SEXUALIDADE E AFETIVIDADE DE ADOLESCENTES COM HIV/AIDS
}

\author{
Luciana França Cescon \\ Universidade Paulista
}

\begin{abstract}
Resumo
O presente trabalho tem como objetivo refletir sobre a influência do HIV/AIDS sobre as relações sociais, a sexualidade e a afetividade de adolescentes. Foi realizado um levantamento bibliográfico e posterior discussão teórica sobre o tema, tendo como metodologia a análise qualitativa de textos e artigos científicos. O estudo dos dados encontrados demonstrou que se faz necessário considerar integralmente os diversos aspectos psicossociais envolvidos nesta dinâmica, uma vez que os aspectos psicológicos influenciam de forma significativa a evolução da doença e a qualidade de vida do paciente soropositivo. No caso dos adolescentes, essa influência torna-se ainda maior, pois a puberdade é uma etapa específica de desenvolvimento biológico, emocional e social, onde a interação social tem papel importante para a construção da personalidade do sujeito. Espera-se que esse estudo possa contribuir para a reflexão sobre a importância de criarem-se estratégias de enfrentamento e acolhimento nas intervenções de saúde voltadas pra este grupo específico, especialmente no que diz respeito à atuação do psicólogo, que deve procurar acolher as demandas destes sujeitos, contribuindo para um desenvolvimento psicossocial saudável, considerandosuas especificidades.
\end{abstract}

Palavras-chave: psicologia, adolescência, AIDS, sexualidade, direitos reprodutivos.

\section{RAPUNZEL'S COMPLEX: SOCIAL RELATIONS, AND SEXUALITY AFFECTIVITY OF ADOLESCENTS WITH HIV/AIDS}

\begin{abstract}
The present work aims to reflect on the influence of HIV / AIDS on social relations, sexuality and adolescent affectivity. We conducted a literature review and subsequent theoretical discussion on the topic, with the methodology of qualitative analysis of texts and scientific articles. The findings of the study demonstrated that it is necessary to fully consider the various psychosocial aspects of this dynamic, since the psychological aspects significantly influence disease progression and quality of life of HIV patient. For adolescents, this influence becomes even greater, because puberty is a specific stage of biological development, emotional and social, where social interaction plays an important role for the construction of the subject's personality. It is hoped that this study may contribute to the reflection on the importance of creating themselves coping strategies and health care interventions geared to this particular group, especially with regard to the psychologist, who should seek to accommodate these demands subjects, contributing to a healthy psychosocial development, considering its specific features.
\end{abstract}

Keywords: psychology, adolescence, AIDS, sexuality, reproductive rights. 


\title{
COMPLEJO DE RAPUNZEL: RELACIONES SOCIALES, SEXUALIDAD Y LA AFECTIVIDAD DE LOSADOLESCENTESCON VIH/SIDA
}

\begin{abstract}
Resumen
El presente trabajotiene como objetivo reflexionar sobre la influencia del VIH / SIDA enlas relaciones sociales, lasexualidad y laafectividad adolescente. Se realizó una revisión de la literatura teórica y el debate posterior sobre el tema, conlametodología de análisiscualitativo de textos y artículos científicos. Los resultados delestudiodemostraron que es necesariotener plenamente encuentalos distintos aspectos psicosociales de esta dinámica, ya que los aspectos psicológicos influyen significativamente enlaprogresión de laenfermedad y lacalidad de vida de pacientes con VIH. Para los adolescentes, esta influencia esaúnmayor, porque lapubertad es una etapa específica deldesarrollo biológico, emocional y social, donde lainteracción social juegaun papel importante para laconstrucción de lapersonalidaddelsujeto. Se espera que este estudiopuede contribuir a lareflexión sobre laimportancia de crearellosmismoslasestrategias de afrontamiento y las intervenciones de salud dirigidas a este grupo en particular, especialmente enrelaciónconel psicólogo, que debe buscar para dar cabida a estas demandas lossujetos, lo que contribuye a undesarrollo psicosocial saludable, teniendo encuenta sus características específicas.

Palabras clave: psicología, adolescencia, SIDA, sexualidad, derechos reproductivos.
\end{abstract}

\section{INTRODUÇÃO}

Adolescência e AIDS: Desafios e perspectivas

O surgimento do vírus HIV transformou de forma muito significativa o comportamento sexual de todas as pessoas, independentemente de idade, sexo ou nível socioeconômico. Só para relembrar, a AIDS (Síndrome da Imuno Deficiência Adquirida) foi diagnosticada pela primeira vez em 1981, e o primeiro caso no Brasil surgiu em 1983. Porém, foi em 1984 que se detectou o retrovírus do HIV como responsável pela deficiência do sistema imunológico dos pacientes. Sua transmissão ocorre através de transfusão de sangue ou pelo contato direto com sangue ou demais fluidos corporais, mas principalmente através da relação sexual (Duarte, 1995).

Em relação à transmissão do vírus, pesquisas têm demonstrado que apesar de toda informação disponível e das campanhas de prevenção, os jovens ainda estão sendo infectados em índices que chamam atenção. Dados do Ministério da Saúde apontam que atualmente mais da metade dos novos casos de HIV ocorrem em jovens de 15 a 24 anos de idade. Estima-se que 11,8 milhões de jovens desta faixa etária vivem na atualidade com HIV/AIDS em todo o mundo. Mais de $20 \%$ da população brasileira é constituída por crianças e adolescentes entre 10 e 19 anos de idade, e essa faixa apresenta uma elevada taxa de risco, uma vez que estatísticas calculam que a cada ano, cerca de 4 milhões de jovens tornam-se ativos sexualmente no Brasil (Brasil, 2006). 
Campanhas de prevenção e conscientização são realizadas sistematicamente, e o acesso à informação torna-se cada vez maior. Porém, é preciso lembrar que faz-se necessário dar a mesma atenção dedicada à prevenção da doença para abordar os cuidados àqueles que são soropositivos e têm que lidar com as conseqüências da soropositividade em sua vida diária. Torna-se cada vez mais claro que é preciso criar estratégias e intervenções que apóiem e tragam qualidade de vida aos pacientes, especialmente no que diz respeito a adolescentes, por apresentarem uma demanda específica. Iniciativas como a elaboração do Manual de rotinas para assistência de adolescentes vivendo com HIV/AIDS, criado pelo Ministério da Saúde em 2006, apontam a relevância de trabalhos neste sentido.

Uma vez que o conceito de saúde foi ampliado para além da ausência de doença, incluindo fatores diversos como qualidade de vida, saúde mental e relações interpessoais, não é por acaso que o psicólogo tem tido uma participação cada vez maior dentro das políticas públicas, especialmente naquelas voltadas para que a população com menos recursos econômicos tenha acesso a esse cuidado psicológico, fundamental para o bem-estar social e para a transformação da realidade. Em equipes interdisciplinares, o psicólogo pode contribuir com os outros profissionais, bem como com os pacientes e sua família, por ter esse olhar mais amplo sobre a dinâmica familiar e demais relações sociais envolvidas. Falar em saúde sem considerar os fatores humanos envolvidos é ignorar a influência dos aspectos psicossociais dentro do contexto da doença, como afirmou Minayo:

[...] no campo da saúde se vivencia a complexidade dos objetos de estudo pois a abrangente área biomédica não pode prescindir da problemática social, uma vez que o corpo humano está atravessado pelas determinações das condições, situações e estilo de vida. (2010, p. 28).

Sabe-se que a puberdade e a descoberta da sexualidade trazem muitos questionamentos e descobertas para todas as pessoas. Além do controle da reprodução, temas como homossexualidade, aborto, masturbação, entre outros assuntos, geram dúvidas e ansiedade nos adolescentes. Mas, quando se trata de jovens que vivem com HIV, todos estes conflitos podem despertar ainda mais angústia. Segundo o Ministério da Saúde (2006), é comum observar por parte dos profissionais, assim como das famílias ou cuidadores, a negação do desejo sexual nos adolescentes que vivem com HIV/AIDS. Há freqüentemente um 
incentivo ao prolongamento da infância destes jovens, fazendo com que aspectos importantes e determinantes da saúde sexual sejam postos de lado, o que pode prejudicar seu desenvolvimento psicológico.

Este artigo tem como objetivo fazer um levantamento bibliográfico sobre o tema e contribuir para sua discussão. Foram selecionados artigos científicos e livros que debatiam especificamente a questão da sexualidade e dos direitos reprodutivos de adolescentes que vivem com HIV, bem como uma bibliografia básica sobre adolescência e sexualidade. A partir dos trechos selecionados, partiremos para uma discussão qualitativa sobre as especificidades do tema, uma vez que não encontramos muitas referências que abordem todos estes subtemas de forma integrada, defendendo ainda nossa visão sobre a relevância de refletir sobre essa problemática específica.

\section{Os Adolescentes e seus direitos psicossociais}

O Estatuto da Criança e do Adolescente (ECA) encontra-se a definição de adolescência como o período da vida que vai dos 12 aos 18 anos de idade. A adolescência, tal como a conhecemos hoje é, até certo ponto, um produto de nosso século. Palácios (1995) destacou a necessidade de se fazer uma distinção entre puberdade e adolescência:

Chamamos puberdade ao conjunto de modificações físicas que transformam o corpo [...] Chamamos de adolescência um período psicossociológico que se prolonga por vários anos, caracterizado pela transição entre a infância e a adultez [...] Além disso, a puberdade é um fenômeno universal, enquanto a adolescência não adota necessariamente, em todas as culturas, o padrão de característica adotada na nossa (p. 265).

Segundo Osório (1992), a adolescência é uma etapa evolutiva peculiar ao ser humano. Nela, culmina todo o processo maturativo biopsicossocial do indivíduo. Para Bee (1997) faz mais sentido pensarmos a adolescência como o período que se situa, psicológica e culturalmente, entre a meninice e a vida adulta, ao invés de uma faixa etária específica. Entretanto, Calligaris (2009) propôs uma abordagem mais psicológica da adolescência. Esse autor ressalta a necessidade de compreendermos esse fenômeno através do modo que ele é sentido e vivenciado pela sociedade. E, nesse sentido, caracteriza a adolescência como um período idealizado pelos adultos, como resultado do desejo originado das exigências da modernidade, de que as crianças e os jovens estendam as expectativas e o sentido da vida para além de cada sobrevivência individual. 
Quanto mais a infância se afasta de um simples consolo estético, quanto mais é encarregada de preparar o futuro, ou seja, de se preparar para alcançar um (impossível) sucesso que faltou aos adultos, tanto mais ela se prolonga. Isso inevitavelmente força a invenção da adolescência, que é um derivado contemporâneo da infância moderna. (p. 67).

Independentemente da concepção adotada, é inegável que a adolescência é uma etapa do ciclo vital humano que apresenta características, transformações e necessidades específicas, e por isso, requer uma compreensão especial. Esta noção torna-se ainda mais importante quando o adolescente é portador de uma doença crônica, que implica em cuidados a longo prazo e risco de vida, aliados a preconceitos e dúvidas, como é o caso da AIDS.

\section{HIV/AIDS: Adolescentes em risco}

Ao longo dos 20 anos de epidemia, a AIDS mudou o perfil dos contaminados e a história natural da doença. Se inicialmente os homossexuais e usuários de drogas eram considerados como grupo de risco, atualmente, a epidemia demonstra uma tendência à feminilização, juvenilização, pauperização e interiorização. Sendo assim, a população mais vulnerável, hoje em dia, é a das mulheres jovens, de nível sócio-econômico mais baixo, do interior do país. (Conselho Federal de Psicologia, 2002, p. 104).

Um aspecto preocupante da doença é que a cada ano os índices indicam um aumento no caso de jovens infetados. Estatisticamente, foi comprovado que mais de $70 \%$ dos casos de AIDS correspondem a indivíduos entre 20 e 39 anos, sendo que uma parcela considerável desses pacientes contraiu o vírus na adolescência (Brasil, 2006).

Outro contexto fundamental quando se fala no apoio e cuidados dos adolescentes é o núcleo familiar. As dificuldades da família em dar suporte ao adolescente vivendo com HIV/AIDS variam em função da forma de aquisição da infecção pelo HIV. Nas famílias em que ocorreu transmissão vertical (durante a gestação ou parto), freqüentemente existem dificuldades relacionadas a perdas de familiares, doença e sentimentos ambivalentes como culpa e castigo. Quando a doença é adquirida por via sexual ou pelo uso de drogas, podem revelar comportamentos nem sempre conhecidos e/ou aceitos pela família e comunidade (Ministério da Saúde, 2006). O suporte da família é a base para a eficácia das ações voltadas para o adolescente, mas não podemos esquecer que a família 
também precisa receber suporte da equipe, para o fortalecimento dos vínculos e melhor enfrentamento do problema.

Desta forma, faz-se necessário considerar que o trabalho de todos os profissionais de saúde deve ser pautado pelos direitos humanos e pela busca da superação de toda e qualquer forma de discriminação. No caso específico do profissional de Psicologia, ele deve incluir em sua atuação intervenções que visem à eliminação ou à diminuição do estigma, preconceito e discriminação, como, por exemplo, a defesa do direito à reprodução, à igualdade de gênero e o acesso ao trabalho, assim como o direito de as pessoas serem tratadas de forma igualitária e de terem acesso a cuidados de prevenção e a tratamento de saúde. (CREPOP, 2008).

Sexualidade na Adolescência: Angústias e prazeres

De acordo com Bock, Furtado e Teixeira (2002), a importância da sexualidade na vida das pessoas teve destaque no campo da Psicologia desde o momento em que Freud, em sua investigação sobre as causas e o funcionamento da neurose, descobriu que a maioria de pensamentos e desejos reprimidos referiam-se a conflitos sexuais originados na infância. A descoberta da sexualidade infantil e sua importância na vida psíquica repercutiram na sociedade da época, mas desde então o estudo sobre a influência dos aspectos sexuais na identidade e bem-estar dos indivíduos tornou-se cada vez mais reconhecida.

Sexo é prazer e desejo, mas principalmente no que diz respeito aos adolescentes, sexo também significa aquilo que é proibido, algo que pode gerar culpa.

"Nesta fase, a questão sexual parece estar sempre no limite entre o desejo e a repressão". (Bock, Furtado, \& Teixeira, 2002, p. 229).

O sexo não se limita apenas o lado instintivo e reprodutivo do ser humano. $\mathrm{O}$ ato sexual, associado a emoções e sensações, traz o sentimento de plenitude e prazer. Quando esses sentimentos são compartilhados, a sexualidade é plenamente vivida (Duarte, 1995). O ato sexual acaba significando um momento de descoberta do próprio corpo e das sensações compartilhadas com outra pessoa. Porém, quando há na história de vida da pessoa uma doença que pode ser transmitida sexualmente, as preocupações sobre o futuro e as dúvidas 
podem gerar uma grande carga de angústia, que acabará prejudicando a vivência plena desta fase.

Quando surgiu a idéia de fazer um estudo sobre a influência da soropositividade na vida de adolescentes, logo associei este conflito ao simbolismo da história infantil "Rapunzel", adolescente que vive presa em uma torre inacessível. Rapunzel, um dos contos de fada que os irmãos Grimm tornaram mundialmente conhecidos, resumidamente, trata da história de um casal que queria muito ter um filho. Quando finalmente acontece a gravidez, a mãe tem o desejo de comer raponços (um tipo de verdura), que a vizinha cultivava. O pai é surpreendido pela vizinha-bruxa quando apanhava a verdura, e para ficar vivo, promete que entregará o bebê à bruxa, assim que ele nasça. $A$ menina é batizada de Rapunzel pela bruxa. Quando a menina completa 12 anos, é presa em uma torre sem portas, onde o único acesso é feito através de suas longas tranças. A única pessoa que vê a jovem é a bruxa, até o dia em que um príncipe ouve Rapunzel e sai à sua procura. Vendo como a bruxa sobe e desce através das tranças, espera que ela vá embora para poder subir também. Iniciase um romance que a bruxa termina por descobrir, e cortando as tranças de Rapunzel espera que o príncipe suba boa parte da altura, jogando-o lá de cima. O príncipe fere seus olhos na queda, e fica cego. Rapunzel é expulsa da torre, e depois de muito sofrimento, os dois se reencontram. As lágrimas de Rapunzel devolvem a visão ao príncipe e assim eles podem viver felizes para sempre.

$\mathrm{Na}$ interpretação de Corso \& Corso (2006), Rapunzel cresce com uma bruxa que age como mãe dedicada até que chega a puberdade, que traz para a filha uma curiosidade de transpor os muros do jardim. É apenas quando a jovem atinge a idade de 12 anos, que a bruxa, temerosa de que alguém visse sua crescente beleza, resolve prender Rapunzel em uma torre, sem portas, que só poderia ser acessada subindo-se pelos cabelos da moça. A mãe-bruxa torna-se o único contato de Rapunzel com o mundo.

Podemos relacionar que a AIDS e suas consequências, como por exemplo, as dúvidas dos cuidadores, o sigilo por medo do preconceito, os estigmas relacionados à doença e a rotina de cuidados médicos, enfim, acabam por tornarse, de forma simbólica, a torre de cada adolescente soropositivo. Na maioria dos casos, o adolescente só pode sentir-se realmente à vontade neste universo protegido, onde as outras pessoas sabem que ele tem a doença, onde ele é compreendido, onde seu diagnóstico é compartilhado. Cria-se uma redoma 
protetora, mas existe também um lado negativo: torna-se mais difícil saber em quem confiar,para quem é possível fazer a revelação do diagnóstico sem correr o risco de perder uma amizade ou sofrer preconceito. Sair deste ambiente protegido, ampliando as relações interpessoais, pode tornar-se um desafio. Por isso, discutir a questão das relações sociais e afetivas dos adolescentes que vivem com HIV, incluindo neste contexto seus direitos sexuais e reprodutivos, pode ajudar a repensar as possibilidades de construção de projetos de vida que ampliem o universo futuro destes sujeitos.

Para ilustrar os conflitos vivenciados pelos adolescentes nesta questão, escolhemos trechos do livro "Depois daquela viagem- Diário de bordo de uma jovem que aprendeu a viver com AIDS". Escrito por Valéria PiassaPolizzi e lançado em 1997, trata-se de um relato autobiográfico no quala autora, que contraiu o vírus da AIDS aos 16 anos, resolveu escrever sua história aos 23 anos, compartilhando suas angústias, dúvidas e seu aprendizado. Foram selecionados alguns trechos do livro para exemplificar as dúvidas do jovem portador de HIV em relação aos outros, no que se refere às relações sociais, afetivas e sexuais, pois a partir da fala de um sujeito, podemos estabelecer relações de pontos comuns e perceber a dinâmica social e histórica de determinado fenômeno. Segundo Aguiar (2001):

... o indivíduo, apesar de ser único, contém a totalidade social e a expressa nas suas ações, pensamentos e sentimentos. Assim, o processo apreendido (e não as manifestações externas; respostas) a partir de um sujeito pode revelar algo constitutivo de outros sujeitos que vivem em condições semelhantes (pág. 140).

Ao saber que resultado do exame de HIV dera positivo, Valéria preocupouse com as conseqüências da doença. A partir do diagnóstico, fica cada vez mais complicado para Valéria vivenciar sua sexualidade de forma natural:

A gente ficou ali, se abraçando e se apertando, seu corpo quente em cima do meu, sua boca molhada beijando a minha. [...] Já estava ficando tarde e eu precisava ir embora. [...] Enquanto ele foi ao banheiro eu fiquei ali no quarto, esperando. [...] e uma palavra de quatro letras que teimava em não sair da minha cabeça. Podia ser am-o-r, mas não era. Era A-I-D-S. Jurei que aquela seria a última vez que a gente ficava junto. E foi mesmo. (Polizzi, 2005, p. 39).

O medo da rejeição fica em uma luta constante com a solidão e a culpa por estar omitindo a verdade das outras pessoas. Verifica-se ainda a influência da doença na interação do adolescente com os demais núcleos sociais. Esta fala de Valéria relaciona-se pesquisas que apontam que um número significativo de adolescentes que vivem com HIV/AIDS acabam abandonando a escola. Por isso, 
é recomendado que os adolescentes tenham acesso à informação e a um atendimento diferenciado, que possa atender às suas especificidades e diminuir os efeitos negativos da doença na sua vida diária.

De acordo com Cória-Sabini (2007), o adolescente que não está seguro em relação à sua identidade e à aceitação de si mesmo apresenta a tendência de se isolar, dificultando o surgimento de novas relações afetivas e evitando interações sociais. Neste caso, a solidão seria uma fuga desenvolvida a partir do medo de não ser aceito pelos outros. Polizzi refletiu este sentimento em outro trecho de seu livro:

Normal? Normal! Acho que isso é tudo o que eu queria ser. Mas vai tentar ser normal ouvindo todo dia a AIDS mata, a AIDS é o mal do século, vamos acabar com a AIDS. [...] Como é que se pode levar uma vida normal ouvindo isso toda hora, lendo isso em todos os lugares? Como é que eu posso pensar em seguir uma carreira, casar, ter filhos, construir qualquer coisa que seja, sendo associada a todas essas coisas horríveis? (Polizzi, 2005, p. 114)

O que torna mais difícil a convivência social é saber que a decisão de se expor ao outro é uma escolha exclusiva do adolescente. Sua doença não aparece fisicamente, muitas vezes ainda não há nenhum sintoma. Porém, cabe a ele compartilhar ou não com os outros sobre sua soropositividade. Esta é uma das questões que exigem que o profissional que atende a esta demanda tenha sensibilidade para abordar ao assunto e ao mesmo tempo, faça pontes que facilitem o diálogo e a expressão de sentimentos e pensamentos que o adolescente traz dentro de si.

\section{Direitos sexuais e reprodutivos: Conflitos e possibilidades}

De acordo com Bock, Furtado e Teixeira (2002), o controle da reprodução é muito importante para qualquer jovem que mantenha um relacionamento heterossexual. Pensar sobre a possibilidade de uma gravidez implica considerar diversos fatores, como a pressão social do grupo de amigos, a pressão da família, o medo, o desejo, e muito mais. E quando se fala sobre os direitos reprodutivos de adolescentes que vivem com HIV/AIDS, esta questão se torna muito mais delicada e complicada.

Paiva e colaboradores (2011) realizaram um estudo qualitativo com o objetivo de compreender como adolescentes e jovens soropositivos lidam com suas experiências sexuais e projetos de namoro, bem como com o desejo de constituir família e de ter filhos. Os resultados apontaram que, de maneira geral, 
mesmo com toda a informação, as pessoas que vivem com HIV de forma geral ainda não são consideradas como aptas a constituir família e permanecem estigmatizadas como perigosas. O resultado disso é que os adolescentes sentem um misto de culpa, dúvida e frustração quando pensam sobre seu futuro social e afetivo.

É importante destacar que quando se discutem os direitos sexuais e reprodutivos de pessoas com HIV/AIDS, parece que o limite entre pessoal e privado se torna mais tênue. O direito de escolha deixa de pertencer apenas ao indivíduo e passa a contar com a intervenção social. Como exemplo, podemos citar o papel do profissional de saúde, que passa a ter um papel mais ativo no processo de reflexão na decisão entre o desejo de ter um filho e as implicações médicas que esta opção pode trazer. Para o adolescente, além do fato de que a gravidez por si só jápode trazer prazer, além de um status social, já que a gestante agora vai ser objeto de atenções e cuidados, às vezes não existentes antes. Na adolescente vivendo com HIV/AIDS, muitas vezes, antes de qualquer coisa, a gravidez vem associada à representação de vida e saúde(BRASIL, 2006).

A própria equipe de saúde acaba muitas vezes transmitindo suas impressões quando o tema surge entre os pacientes. Oliveira e França Junior (2003) fizeram uma pesquisa sobre as demandas reprodutivas de pessoas com HIV/AIDS e seu impacto no contexto de saúde. Observaram que de modo geral, a primeira reação dos profissionais era de atribuir a gravidez da paciente à falta de informação. Havia uma dificuldade em perceber que a sorologia não impedia que os ideais de maternidade aflorassem naturalmente nas futuras mães.

É possível pensar que neste caso há um estigma, como definido por Goffman (1975), na situação de um indivíduo que está inabilitado para a aceitação social plena. No caso do adolescente ou jovem adulto que vive com HIV/AIDS, há uma restrição social implícita, que impede ou dificulta que a decisão sobre ter ou não filhos seja exclusivamente sua.

As relações sociais também ficam prejudicadas nesta situação. Os estigmas e preconceitos relacionados ao HIV/AIDS ainda são muito fortes.

As pessoas falando alto, rindo, brincando. [...] Era sempre assim, tudo muito legal, muito bonito. Aí, de repente, eu começava a olhar tudo como se eu não fizesse mais parte de nada, como se tudo aquilo fosse uma cena de filme e eu estivesse de fora assistindo. E aí eu olhava para aquelas pessoas e começava a me perguntar: se essas pessoas soubessem que eu tenho AIDS, será que elas estariam aqui comigo? Será que teriam jantado comigo, na mesma mesa? (Polizzi, 2005 , p. 85). 
Abrir espaço para que estes questionamentos possam ser expressos pelos adolescentes é muito importante, por isso acredito que é preciso ampliar o diálogo e o planejamento de intervenções para muito além da adesão ao tratamento e aos cuidados relacionados à doença. Os grupos são uma boa opção para que a subjetividade desses jovens possa ser expressa e compartilhada, não apenas entre si, mas também com os cuidadores e profissionais.

\section{CONSIDERAÇÕES FINAIS}

Este trabalho originou-se de um pré-projeto para pesquisa de Mestrado em Saúde Coletiva. Minha intenção é dar continuidade a ele, quiçá em breve, fazendo uma pesquisa de campo envolvendo os três grupos considerados no levantamento bibliográfico deste estudo: adolescentes soropositivos, profissionais de saúde e cuidadores. Acredito que os diferentes pontos de vista enriquecerão a discussão do problema, trazendo uma compreensão global sobre as representações dos diversos grupos envolvidos nesta questão.

Por ser uma doença crônica que exige cuidados intensivos e de longo prazo, a pessoa que vive com HIV recebe atenção de uma equipe multidisciplinar. Entendemos que o papel do psicólogo torna-se ainda mais importante neste contexto, porque ele pode fazer a ponte entre o adolescente e sua realidade, favorecendo para que este possa sair do isolamento de sua torre e assimexperiencie novas possibilidades de socialização e relacionamentos interpessoais. Acreditamos que o profissional de Psicologia deve pautar sua atuação considerando a questão da vulnerabilidade e dos direitos humanos, tendo sempre uma boa escuta para atender as demandas que vão além da questão da convivência com a doença. Deve ter como norte em seu trabalho a sensibilidade e a prontidão para acolher não só o adolescente, como também seus cuidadores, enfatizando em sua fala que ele, como profissional, não pode oferecer respostas prontas ou padronizadas, mas que pode ajudar na construção de formas de enfrentamento e de superação, de acordo com a necessidade de cada caso.

Sawaia (2002) afirmou que a exclusão vista como sofrimento de diferentes qualidades recupera o indivíduo perdido nas análises econômicas e políticas, sem perder o coletivo. Dá força ao sujeito, sem tirar a responsabilidade do Estado. Éno sujeito que se objetivam as várias formas de exclusão, a qual é vivida como motivação, carência, emoção e necessidade do eu. Por isso, deve ser dedicada 
uma atenção especial à questão das relações sociais, a sexualidade e a afetividade de adolescentes, pois cada sujeito deve ser visto de forma integral, e não apenas no que se refere à sua doença e adesão ao tratamento.

Acreditamos que é preciso pensar em estratégias que permitam ampliar as possibilidades do adolescente que vive com HIV nos mais diversos contextos, para assimfavorecer mais qualidade de vida na convivência social, visando a promoção não apenas da saúde, mas também da cidadania e dos direitos humanos.Refletir e colocar em pauta a discussão da sexualidade, das relações sociais e dos direitos reprodutivos do adolescente que vive com HIV é abrir as portas para um assunto que ainda não é tão discutido quanto deveria, pois esta questão é importante e diz respeito a um direito que deve ser respeitado.

\section{REFERÊNCIAS}

Aguiar, W. M. J. (2001). A pesquisa em psicologia sócio-histórica: contribuições para o debate metodológico. In: Bock, A. M. B., et al. Psicologia sóciohistórica: uma perspectiva crítica em psicologia. São Paulo: Cortez.

Bee, H. (1997). O ciclo vital. Porto Alegre: Artes Médicas.

Bock, A. M. B., Furtado, O., Teixeira, M. L. T. (2002). Sexualidade. In: Boack, A.

M. B., et al. Psicologias: Uma introdução ao estudo de Psicologia. (p. 229244). São Paulo: Saraiva.

Brasil. Ministério da Saúde. (2006). Secretaria de Vigilância em Saúde. Programa Nacional de DST e Aids. Manual de rotinas para assistência de adolescentes vivendo com HIV/Aids. Brasília: Ministério da Saúde.

Calligaris, C. (2009). A adolescência. São Paulo: Publifolha.

Cória-Sabini, M. A. (2007). Psicologia do desenvolvimento. São Paulo: Ática.

Corso, D., \& Corso, M. (2006). Fadas no divã. Porto Alegre: Artmed.

CREPOP - Centro de Referência Técnica em Psicologia e Políticas Públicas (2008).

Referências técnicas para a atuação do(a) psicólogo(a) nos Programas de DST e AIDS. Conselho Federal de Psicologia (CFP). Brasília.

Conselho Federal de Psicologia (2002). Adolescência e Psicologia: Concepções, práticas e reflexões críticas. Disponível em: http://www.crprj.org.br/publicacoes/cartilhas/adolescencia.pdf. Acessado em maio/2012.

Duarte, R. G. (1995). Sexo, sexualidade e doenças sexualmente transmissíveis. São Paulo: Moderna. 
Goffman, E. (1975) Estigma: Notas sobre a manipulação da identidade deteriorada. Rio de Janeiro: Zahar.

Minayo, M. C. S. (2010). O desafio do conhecimento. São Paulo: Hucitec.

Oliveira, L. A., França Junior, I. (2003). Demandas reprodutivas e a assistência às pessoas vivendo com HIV/AIDS: limites e possibilidades no contexto dos serviços de saúde especializados. Caderno de Saúde Pública, Rio de Janeiro, 19(2), 315-323. Disponível em: http://www.scielo.br/pdf/csp/v19s2/a13v19s2.pdf.

Osorio, L. C. (1992). O que é adolescência, afinal? In: Adolescente hoje. Porto Alegre: Artmed.

Paiva, V., et. al. (2011) A sexualidade de Adolescentes vivendo com HIV: direitos e desafios para o cuidado. Ciência \& Saúde Coletiva, 16(10), 4199-4210. Disponível em:http://www.scielo.br/pdf/csc/v16n10/a25v16n10.pdf. Acessado em Maio/2012.

Palácios, J. (1995) O que é a adolescência. In: Coll, C., Palácios, J., \& Marchesi, A. (Orgs). Desenvolvimento psicológico e educação: Psicologia evolutiva. ( $p$. 263-272). Porto Alegre: Artes Médicas.

Polizzi, V. P. (2005). Depois daquela viagem: Diário de bordo de uma jovem que aprendeu a viver com AIDS. São Paulo: Ática.

Sawaia, B. (2002). O sofrimento ético-político como categoria de análise da dialética exclusão/inclusão. In: As artimanhas da exclusão: uma análise ético-psicossocial. (p. 97-127). São Paulo: Vozes.

Contato: Iucianacescon@yahoo.com.br

Recebido em: 25/02/2012

Revisado em: 23/04/2012

Aceito em: 02/06/2012 